\title{
Summit: vague answers to well-known problems?
}

\author{
Multinational negotiations can work, but not where local people are causing the problem.
}

Sir - Two types of environmental problem resist solution by multinational summits such as the Johannesburg Summit on Sustainable Development (see V. Gewin, Nature 417, 475; 2002). First are local problems that cannot be managed through global mandates; second are global problems that impinge on domestic authority.

Many 'global' problems are actually local ones with global implications, such as deforestation and desertification. Multilateral negotiations are ineffective in this case: the Convention on Deforestation will not stop a poor farmer cutting down a tree for firewood; declarations on sustainable development will not change North America's appetite for consumption.

Second, summits sponsored by bodies such as the United Nations (UN) have a mandate to respect national sovereignty. But in many fields this conflicts with policymaking. Climate-change negotiations have been challenged by nations worried about the effects on domestic policy. In multilateral trade agreements, the World Trade Organization (WTO) forbids differentiation of traded goods on the grounds of their production methods, so environmentally beneficial standards cannot become the basis of trade policy.

To address local problems: transferring technology and reducing poverty may be the best way of promoting good environmental management in poorer countries.

To address state sovereignty: the International Commission on Intervention and State Sovereignty's report, The Responsibility to Protect (www.iciss-ciise.gc.ca/ reporte.asp), lays out the principles and conditions whereby this is subordinate to humanitarian causes. We can conclude that states have the same responsibility to protect their people from environmental threats as from military threats. If environmental problems affect many people, the international community should have the mandate to mediate solutions. This could have helped the 50,000 in Malaysia affected by Indonesia's forest fires in the 1990s.

We also need strong national legislation to ensure that the environmental costs of business are reflected in prices, and that trade policy supports production methods that absorb environmental costs.

Judging from the preliminary draft documents for Johannesburg, all we can expect is another declaration about the problems we face, coupled with grand, imprecise solutions. The problems were well articulated 30 years ago at the first UN environment summit; surely it is time to assess the strengths and weaknesses of summits in areas where diplomacy fails to promote environmental governance and devise appropriate new strategies. Evan D. G. Fraser, Warren Mabee The Liu Centre for the Study of Global Issues, 6476 Northwest Marine Drive, Vancouver, British Columbia V6T 1Z2, Canada

\section{Physicists take issue of misconduct seriously}

Sir - The News Feature "Time to wise up?" (Nature 418, 120-121; 2002) concludes, in the light of recent allegations about results from Bell Labs, that physical scientists' organizations are not tackling misconduct.

You quote an excerpt from a statement by the American Physical Society (APS) and comments by an APS spokesperson. These do not provide an accurate picture of APS policy. Our 1987 statement (see www.aps.org/statements/87.1.html) comments on why physicists may not have felt a need for a misconduct policy in the past. But you do not mention our 1991 guidelines for professional conduct (see www.aps.org/statements/91.8.html), an omission that may give readers the erroneous impression that the APS has never adopted a code of ethics.

The 1991 guidelines cover the types of alleged misconduct now being investigated. They state: "Fabrication of data or selective reporting of data with the intent to mislead or deceive is an egregious departure from the expected norms of scientific conduct." The spokesperson's comment that the APS "has no specific plans to revise its misconduct policies at this time, but is always alert to making changes in the future" should be read in this context. If events show that these guidelines are incomplete, the APS is prepared to revise its policies or take other appropriate action. William F. Brinkman

American Physical Society, 1 Physics Ellipse, College Park, Maryland 20740, USA

\section{Fraud: the system works}

Sir-Your News Feature (Nature 418, 120-121;2002) seems to try to shift the blame for the "Schön affair" to the scientific community. We have followed this work since the first publications. The answer to your question of whether we are ready to police ourselves is simple. The scientific system is working. Physical scientists do police themselves: not only is the scientific community ready to "tackle the issue of misconduct", it has already done so.

Problems with the Bell Labs data (see Nature 417, 789; 2002) were uncovered by physical scientists asking tough questions months before journalists got a hint of them. The impression left by your article, that we were taken for a ride, could not be farther from the truth. Journalists have blown things out of proportion, while scientists were trying to reproduce results.

It is not easy to identify such problems and it takes time for the system to kick in. The results Schön et al. presented were not unreasonable: several groups have observed similar (although much smaller) effects over more than 20 years. It is still not clear whether there has been any fraud; the possibility exists, however unlikely, of an experimental mistake. This will eventually be settled by the investigating committee.

Natural science has a self-regulating system that has evolved over centuries. Sooner or later the true facts about claimed physics phenomena are revealed by a worldwide iteration process by diverse research teams. This system works. Ivan K. Schuller ${ }^{\star}$, Gernot Guentherodt $\dagger$ *Department of Physics, University of California, San Diego, La Jolla, California 929093, USA $\dagger I I$ Physikalisches Institut, Rheinisch-Westfalische Technische Hochschule, 52056 Aachen, Germany

\section{Impartial review is key}

Sir - Your News Feature (Nature 418, 120-121; 2002) raises important issues that the physical-science community must face. Argonne National Laboratory's code of ethics calls for a response very similar to that of Bell Labs, namely: "The Laboratory director may appoint an ad-hoc scientific review committee to investigate internal or external charges of scientific misconduct, fraud, falsification of data, misinterpretation of data, or other activities involving scientific or technical matters." Such a response, giving ample opportunity for all sides to be heard by a panel of disinterested experts, is a natural and effective means of dealing with cases of possible misconduct. George Crabtree

Materials Science Division, Argonne National Laboratory, Argonne, Illinois 60439, USA 